\title{
The Reality of Malaysian ESL Teachers' ICT Pedagogical Practices: Challenges and Suggestions
}

\author{
Liew Wai Kit ${ }^{1}$, Malini Ganapathy ${ }^{1}$ \\ ${ }^{1}$ School of Langugaes, Literacies and Translation, Universiti Sains Malaysia \\ Correspondence: Dr. Malini Ganapathy, School of Languages, Literacies and Translation, Malaysia.
}

Received: August 22, 2019

Accepted: Sep. 12, $2019 \quad$ Online Published: Sep. 15, 2019

doi:10.5430/elr.v8n3p39

URL: https://doi.org/10.5430/elr.v8n3p39

\begin{abstract}
Teachers of English as a second language (ESL) are nowadays exploring the integration of Information and Communications Technology (ICT) tools into their Higher Order Thinking (HOT) pedagogical practices. However, there are various challenges in using ICT to teach Higher Order Thinking Skills (HOTS), as it is only explored superficially. This study investigates the challenges encountered by ESL teachers when using ICT to promote HOTS. Meanwhile it aims to provide a set of guidelines to help teachers in teaching HOTS through utilising ICT. The framework of the research is grounded on Bloom's Revised Taxonomy (2011). 30 ESL teachers from 5 schools selected by the ESL Master Teachers' affiliation, participated in answering to the questionnaires. Meanwhile, 5 ESL teachers from each school were involved in focus group discussions (which were used to triangulate the data obtained from the questionnaires. The FGDs lasted for 20 minutes per session, and they were conducted based on the availability of the ESL teachers. The collected data were analysed in the form of tables and direct excerpts. The findings support that ESL teachers face multiple challenges such as time constraint, poor internet connection, and lack of ICT tools while using ICT to promote HOTS in schools. The findings of the present study are in-line with Malaysia's vision in shifting the focus of education into the acquisition of HOTS. ESL teachers benefit from this research as they can improve on their teaching pedagogies based on the suggestions presented in this study.
\end{abstract}

Keywords: English as a Second Language, higher order thinking, information and communication technology, pedagogical practices, bloom's taxonomy, teachers

\section{Introduction}

The latest advancement in Information and Communications Technology (ICT) has significantly enhanced the efficiency of many areas, such as education, management, and eco-tourism (Hilbert, 2015). The Ministry of Education Malaysia (MoE) (2017) initiated the Education 4.0 framework in tandem with the requirements of the 4th Industrial Revolution. The Education 4.0 framework highlights the vastly improved academic and technical and vocational education and training programmes in many areas (Zakri, 2017). Newer discoveries on ICT's utilisation in education have equipped students with more chances to apply knowledge in their daily lives. Rajeendram (2018) postulated that Malaysia is currently following the flow of global trends with more efficient teaching practices being discovered and higher teaching standards being targeted. Omar (2017) also stressed that the 4th Industrial Revolution is expected to create a conducive environment for learners, academics and practitioners, which will optimise their potential in imagination, innovation, creativity, and collaboration, hence fulfilling the requirements of the latest institutional contexts.

\subsection{Explore Importance of the Problem}

In order to reinforce the focus of recent educational shift on ICT utilisation, the 2017 Budget gifted free tablets to 430,000 teachers for lowering their substantial workload (Malaysia Budget 2017). Teachers struggle to acknowledge the importance of HOTS and the teaching methods, especially since HOT questions are administered in examinations (Hwa, 2016). Teachers are given the responsibility to equip students with the necessary skills to answer the HOT-focused examinations (Rajeendram, 2018). Sharmila et al. (2017) also suggests that teachers have to cope with various difficulties in teaching the HOTS syllabus to students in schools.

Many teachers are still oblivious of the importance of HOT pedagogical knowledge (Guerriero, 2014). Teachers are unfamiliar with the importance of teaching HOTS such as equipping the younger generation with the mandatory 
skills to thrive in the 21st century since the extent to which HOTS are taught and assessed in schools is still questionable (Collins, 2014). English language teaching has not achieved the expected outcomes for pedagogical optimisation (ICFES, 2009).

\subsection{Problem Faced by ESL Teachers}

In fact, the lack of resources for enhancing teachers' professional knowledge of HOTS and their HOT pedagogical knowledge is a major hindrance in achieving the targeted outcomes for teaching and learning (Zohar, 2013). The learner-centred approach should be stressed in schools, whereby teachers are mere facilitators to promote the active acquisition of critical skills, in which students search for answers and solve problems by their own accord. ICT is an effective platform which empowers learners in the process of HOTS acquisition (Savery, 2015). In addition, ICT extends the limits of classroom activities and learning experiences, especially in the application, evaluation, and creation of knowledge acquired from classroom activities (Hammond, 2014).

\subsection{Objectives of the Study}

The research objectives of the study were to examine different challenges ESL teachers encounter in using ICT to promote HOTS, in the English language classroom at selected secondary schools in Penang, Malaysia. The study also aimed to find out the frequency of challenges encountered by ESL teachers when promoting HOTS via ICT utilisation.

\subsection{Bloom's Taxonomy}

The conceptual framework of the study is grounded on three concepts: Bloom's taxonomy, sociocultural theory,and constructivist approach. Revised Bloom's (2011) taxonomy of learning is a revamp of the original Bloom's taxonomy (1956). HOTS are higher tier skills, namely, analysing, evaluating and creating. The first higher level cognitive skills is analysing, that is the ability to summarise the knowledge framework, categorise them, and to detect the relationships between the instruments in the knowledge structure (Marzano \& Kendall, 2006).

Regarding evaluation, learners are expected to possess certain skills such as explaining, analysing information critically, and making judgments in terms of relevancy and consistency (Forehand, 2010). However, the highest level is creating. It centres on the formulation of a completely new structure. Nevertheless, students nowadays do not have enough opportunities to indulge in discussion and sharing of ideas. Hence, many students lack the chance to engage in HOTS, as only the most able student completes most of the group work (Nguyen et. al, 2017).

The present study is only concerned with analysing, evaluating, and creating as the three higher-level skills of Bloom's taxonomy. Teachers need to teach students how to analyse, apply and evaluate information as these skills are vital for the students to excel in public examinations, such as Penilaian Menengah Rendah (PMR) and Sijil Pelajaran Malaysia (SPM).

\subsection{Constructivist Approach}

The constructivist approach advocates that prior knowledge assists in the acquisition of active meaningful learning. ESL teachers in secondary schools must teach students how to apply their prior knowledge in solving problems. Students require prior knowledge especially with their ICT experience, which can help them learn information easier (Loyens et al. (2012). Also teachers' prior knowledge of ICT and their exposure to HOT pedagogies can affect whether they are able to effectively teach HOTS in their classes. This is supported by the constructivist approach which stresses that learning only occurs when learners actively search for new information. Therefore, the ESL teachers' role is to organise the main ideas which engage students' interest to actively search for the information via ICT utilisation, thus, promoting the acquisition of HOTS.

\subsection{Sociocultural Theory}

Vygotsky's (1963) sociocultural theory states that the interaction between teachers and students in learning and teaching activities in schools is crucial to the acquisition of HOTS. The scaffolding concept is important as teachers are only facilitators to students in guiding the them to acquire HOTS. The use of ICT can be evidently seen through Vygotsky's sociocultural theory as the interaction between teachers and students can be made easier through ICT. Students and teachers can connect with each other through the internet, share information and discuss HOTS related issues better.

\subsection{Past Studies on Teachers'HOT Pedagogical Practices}

It is evident in Ganapathy and Kaur's study (2014) that teachers in Malaysia are lacking in terms of pedagogical knowledge and expertise to innovate their lessons with HOTS. Teachers are still not familiar with HOT teaching 
pedagogies in the ESL context. Therefore, many students struggle to answer the HOTS-focused questions in public examinations. The findings of the study reflect an existing gap in the implementation of HOTS in schools. Thus, teachers were encouraged to educate students to use real-world contexts and modify them according to the students' skill levels. Students have the skills to apply the obtained knowledge and therefore, they should be able to internalise the abstract conceptual implication after being exposed to a variety of contextual settings. The study highlighted that teachers are advised to teach in contexts advocating various skills, such as building background knowledge, classifying information into categories, arranging items along some dimension, making hypotheses, drawing inferences, analysing information into components and solving problems. The study suggests that students should also be aware of the strategies they use to analyse, classify or arrange the information. The study proved that teachers have a niche in assuring that their pedagogical practices incorporate the subject matter with HOTS, which facilitate students' engagement and attract their attention simultaneously. With this factor in consideration, teachers' creativity can be improved by engaging students with real-world problems to cultivate the students' HOTS. Ganapathy and Kaur (2014) highlighted that teachers play an important role in ensuring assessments and classroom exercises, whereby they incorporate realistic contexts and problems to promote HOTS as application skills among students in the ESL classroom According to the study, the majority of the students were interested in using Facebook to search for information by chatting with friends. This proves that ICT is capable of promoting HOTS as students can actively obtain and analyse information via the Internet. Ganapathy and Kaur's study (2014) found that motivation and engagement levels were high among students throughout the learning process which involves all the domains in Bloom's taxonomy.

However, Fischer's (2011) study suggested contradictory results. The study pointed to the level of concentration that teachers give to HOTS during their teaching and planning. While respondents asserted that they integrate HOTS in their lessons, the quantitative findings were not in line with what was being observed during their teaching. There were teachers who mentioned that they allocated sufficient wait time during class discussions. Almost every teacher in the study mentioned that active discussions were commonly held in their classes. However, the appropriate wait time was not frequently recorded in the observation data. Although teachers acknowledged the value of instruction for thoughtfulness, their responses showed that they only understood it partially. It means that having experience in teaching, assessment training, as well as exposure to HOTS will benefit the teacher's grasp of HOT pedagogies. (Hargreaves, Earl, \& Schmidt, 2002).

Past research showed that the lack of training and exposure are the reasons why teachers are reluctant to focus on HOTS in their lessons. As teachers are not well-versed in HOT pedagogies, they carry the responsibility to update themselves with the latest curriculum and to introduce HOT activities in the ESL classroom via ICT. Time constraints also discouraged teachers from integrating HOTS into classroom activities. However, the recent implementation of ICT in schools enables teachers to engage students in group activities featuring HOTS, especially in real-life contexts. Therefore, ICT improves the teaching and learning of HOTS in schools and colleges, as highlighted by Ali (2012) and Yee et al. (2012).

Ali's (2012) study discovered that most lecturers possess average to advanced proficiency of ICT knowledge and skills. The lecturers who participated in the study stated that they were exposed to application software such as desktop applications, presentation software, internet applications, and media communication. This finding contradicts with a past study conducted by Bakar and Mohamed (1998) in Malaysia. The earlier study showed that teachers were not literate in computers or computer software usage. Meanwhile, a study in the USA conducted by Kotrlik, Harrison, and Redmann (2000) on vocational teachers found that vocational education teachers only have the mediocre general information, and technical knowledge and skills. The rapid advancement of ICT could lead to these inconsistencies, as ICT is progressively becoming a bigger part of our lives. As shown by previous studies, teachers are still not ready to utilise ICT in teaching and learning contexts as they have not mastered the necessary skills, knowledge, and confidence (Russell, Finger, \& Russell, 2000).

\subsection{Challenges Faced in Incorporating HOT Pedagogies into ESL Classrooms}

The challenges in implementing HOT pedagogies in English language learning classrooms can be analysed through the few concepts. The environment can be challenging for teachers who utilise ICT to promote HOTS/,/ as planning HOT-focused objectives can be time consuming, requiring prior knowledge on the use of certain ICT. ICT orientations in promoting HOTS in the ESL classroom include the use of the Internet, Web 2.0, power point and other technologies. Furthermore, group discussions, critical thinking scenarios/,/ and many HOTS activities can be promoted through ICT. The present study aims to investigate the challenges of implementing HOT pedagogies in English language learning contexts by interviewing ESL teachers, since they provide a deeper insight into the challenges they encounter in the ESL classroom. 


\section{Method}

This study is part of a larger study, featuring the case study method design. The study highlights on further understanding and awareness of Malaysian ESL teachers' ICT and HOT pedagogical practices.

The study was limited to only 5 schools in Penang and 30 ESL teachers answered the questionnaires. Purposive sampling was used to select the respondents accordingly.

The questionnaire was adapted from Ganapathy's (2017) study, as the past study is relevant and it focuses on HOT pedagogical practices in universities. However, the instrument was adapted for ESL teachers in secondary schools instead of universities.

There is triangulation of data as both quantitative and qualitative data are featured in the study. This study aimed to investigate two research questions/in order to achieve effectively the objectives of the study.

\subsection{Participant (Subject) Characteristics}

25 ESL teachers took part in the focus group discussions (FGD) and each discussion session lasted for 20 minutes, featuring 5 ESL teachers from the respective schools. The interviewees in the FGDs were labelled as T (1-5), while the schools were named as S (A-E). The FGDs were used to triangulate the quantitative data.

\subsection{Sampling Procedures}

Due to the different schedules of school teachers, date and time were pre-planned before the interviews were conducted. The venues of the FGDs were dependent on the ESL teachers. The researcher recorded the FGDs and took down notes throughout the interviews. The researcher and interviewees sat close to each other in a circular or square table. This positioning enabled participants to voice out their opinion and thoughts while sharing them with their colleagues. The results of the questionnaire were analysed using SPSS Ver 22 while the results of the focus group discussions were transcribed from the audio recorders. The results of this research do not address the respondents with their actual names and are referred to as Teacher Group A-F.2.3.1

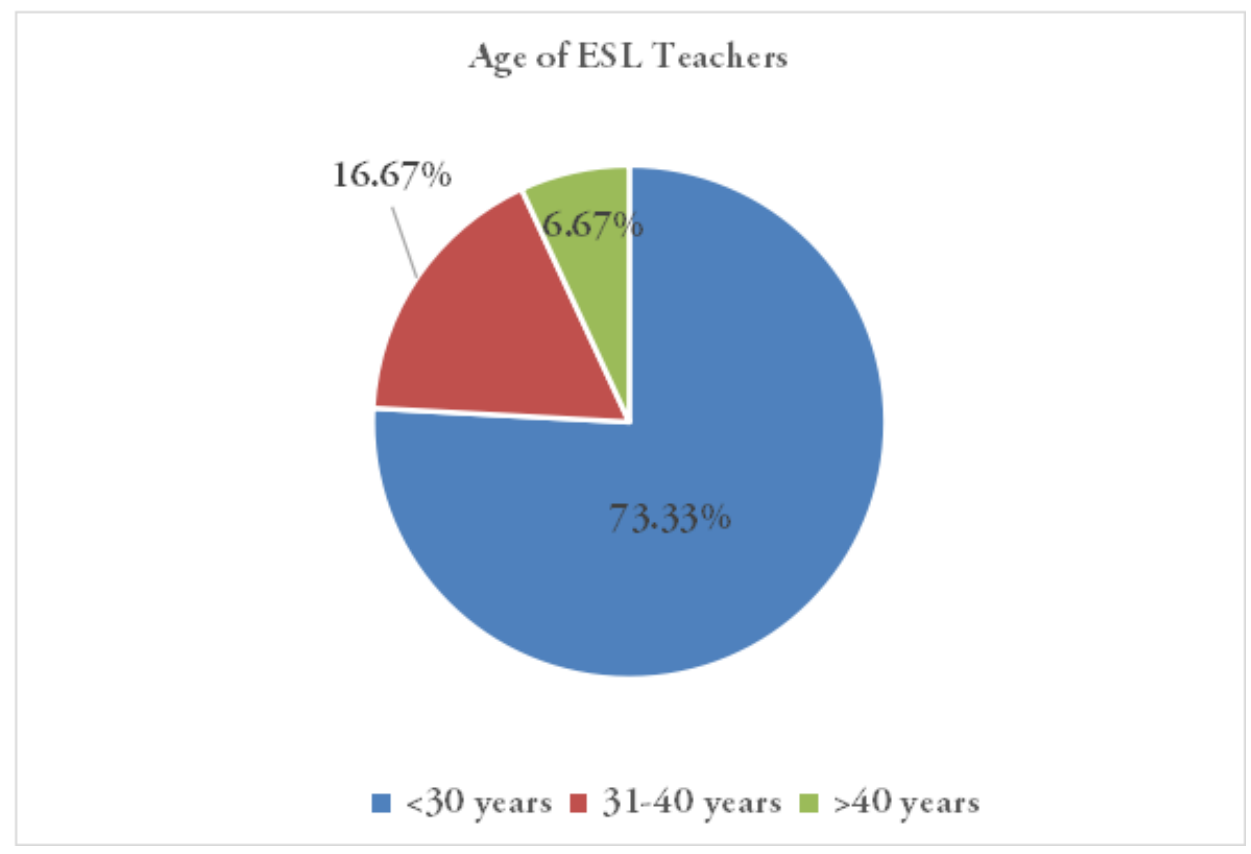

\section{Results}

Demographic Information of Respondents

Purposive sampling was used for data collection as ESL teachers with less than 5 years of teaching experience were selected for this study. From the pie chart above, most (73\%) of the ESL teachers (73\%) are below 30 years old, as teachers above 40 years old usually have more than 5 years of teaching experience. Only 2 (7\%) of ESL teachers in this study are above 40 years old. Younger teachers are prioritised for the study as they should be exposed to the importance of ICT utilisation and HOT teaching pedagogies in the 21st Century. 
Both frequency and types of challenges experienced by ESL teachers /when/ using ICT to teach HOTS can be determined from the collected data. Likert scale from Strongly Agree to Strongly Disagree was utilised in the questionnaire items.

\subsection{Statistics and Data Analysis}

Table 1. Extent of Difficulty in Teaching HOTS

\begin{tabular}{lcccc}
\hline Types of Difficult Criteria & Agree & Valid Percent & Disagree & Valid Percent \\
\hline $\begin{array}{l}\text { Difficult to Adapt from } \\
\text { Old to New Teaching } \\
\text { Format }\end{array}$ & 14 & 46.7 & 16 & 53.3 \\
\hline $\begin{array}{l}\text { Difficult to Teach HOTS } \\
\text { Using ICT }\end{array}$ & 14 & 46.7 & 16 & 53.3 \\
\hline $\begin{array}{l}\text { Difficult to Incorporate } \\
\text { Online Information into } \\
\text { Activities }\end{array}$ & 8 & 26.7 & 22 & 73.3 \\
$\begin{array}{l}\text { Difficult to Access } \\
\text { Netbooks and } \\
\text { Computer Rooms }\end{array}$ & 21 & 70 & 9 & 30 \\
\hline
\end{tabular}

Table 1 above shows that there are 14 (47\%) respondents who agree that they face difficulties to adapt from the traditional teaching format into the new teaching method. In a similar vein, almost half (47\%) of teachers agree that they have to handle difficulties when attempting to teach HOTS using ICT. However, only 8 (27\%) respondents face difficulties in incorporating online information into activities as most $(73 \%)$ of them disagree that incorporating online information into activities is a significant challenge. A majority $(70 \%)$ of teachers agree with the difficulty in accessing netbooks and computer rooms. The results show that ESL teachers are still facing varying difficulties from different challenges in teaching HOTS via ICT.

From the qualitative data, ESL teachers from School A-E confirmed in the focus group discussions that they have model HOTS lesson plans provided by the government. The model lesson plans are provided but the teachers still face difficulties in adapting from their traditional method of teaching.

The ESL teachers in the interview from School E mentioned that:

"We encountered issues as we cannot completely change from the old school format into something new in a brief time. We need time to adapt just like when they changed from English into Bahasa Melayu for certain subjects". [T1: $\mathrm{SE}]$

One of the ESL teachers from School A asserted that:

"We have model HOTS lesson plans given by the government. We also need to upload files and log in frequently into our FrogVLE. The guides are on-sitel,/ so we can read them as long as we have access to the internet". [T1: SA]

ESL teachers from School E are aware of the difficulty to teach HOTS via ICT even when they acknowledge the effectiveness of the more up-to-date teaching via ICT method.

The ESL teachers from School C commented that:

"We sometimes show videos of professional speakers, but we generally avoid this activity. We need to bring the students into the specific ICT laboratories to watch with them and this will require a lot of time and planning as we need to book the place as well". [T1: SC].

From the focus group discussions, the main challenge for incorporating new interesting information and creating interactive activities in the classroom through ICT is the unreliable loading speed of the internet and online applications. One of the ESL teachers mentioned that:

"Our school is equipped with internet and we often use Whatsapp to communicate and update the group for meetings and activities. However, the internet connection is still not stable because there are too many people using it. There are many staff using them here and in the office. We need a good connection to load videos and sometimes we just get frustrated." [T1: SA]

ESL teachers from School C-E support the quantitative results as they stressed on the lack of necessary ICT tools to utilize the model HOTS lessons plans given by the government. One of the ESL teachers from School C postulated that: 
"We do not have good internet quality here in our schools because we are in rural areas. The telecommunication coverage here is bad and the students do not know how to use computers because they do not have them at home. They are from rural backgrounds, but they are just as interested as any other student on interesting news". [T1: SC]

Table 2. Types of Inadequate Resources

\begin{tabular}{|c|c|c|c|c|}
\hline $\begin{array}{c}\text { Types of Insufficient } \\
\text { Criteria }\end{array}$ & Agree & Valid Percent & Disagree & Valid Percent \\
\hline Lack of ICT Skills & 16 & 53.3 & 14 & 46.7 \\
\hline $\begin{array}{l}\text { Lack of Time and } \\
\text { Too much Effort } \\
\text { Required }\end{array}$ & 20 & 66.7 & 10 & 33.3 \\
\hline Lack of Training & 17 & 56.7 & 13 & 43.3 \\
\hline Lack of Awareness & 23 & 76.7 & 7 & 23.3 \\
\hline Lack of Experience & 11 & 36.7 & 19 & 63.3 \\
\hline $\begin{array}{l}\text { Lack of Reliable } \\
\text { Internet Quality }\end{array}$ & 17 & 56.7 & 13 & 43.3 \\
\hline $\begin{array}{l}\text { Lack of Netbooks } \\
\text { and Computers }\end{array}$ & 17 & 56.7 & 13 & 43.3 \\
\hline $\begin{array}{l}\text { Lack of Guidance } \\
\text { and Support }\end{array}$ & 7 & 23.3 & 23 & 76.7 \\
\hline Lack of Experience & 11 & 36.7 & 19 & 63.3 \\
\hline
\end{tabular}

The data in Table 2 indicate that slightly over half of the total respondents (53\%) agree that they lack the necessary ICT skills to promote HOTS. Most (77\%) of the respondents agree that they are not aware of the utilities provided by ICT applications. A similar pattern is seen in the lack of time needed and the excessive effort required in planning HOTS lessons via ICT tools. The lack of reliable network quality and the lack of netbooks and computers are also common challenges faced by ESL teachers in promoting HOTS, with over half (57\%) of the respondents who agree that these are major hindrances in their attempt of using ICT tools to teach HOTS. The result also show that there are still quite a large number (53\%) of ESL teachers who lack the necessary ICT skills to promote HOTS.

In the focus group discussions, a representative from School E highlighted the lack of experience in using ICT to promote HOTS. An ESL teacher from School E mentioned that:

"We know ICT and HOTS are important, but we could not effectively implement the new HOT pedagogies. We are more comfortable in the old format and we do not have enough ICT tools in this school”. [T1: SE]

The focus group discussions also point to the fact that it takes too much time and effort to integrate ICT into HOT pedagogies. This finding is in line with the responses given by ESL teachers from School A who mentioned that:

"Even though our school is equipped with the internet, we still cannot have a perfect connection because many teachers are using them at the same time. Chalk and talk is easier. Yes, we need more time to produce slides and lesson plans online". [T1: SA]

However, in the focus group discussions, the ESL teachers from all 5 schools in this research agreed that they participate in conferences to update themselves on the latest teaching pedagogical practices, which coincides with the quantitative results. The quantitative results show that only $(23 \%)$ of the respondents stress on the lack of guidance and support provided in using ICT to teach HOTS. An excerpt from an ESL teacher in School A mentioned that:

"Every once in a while there will be conferences. Usually there will be some teachers who attend the conferences. After that, we will always discuss and share the information obtained from the conferences".

The ESL teachers have the same opinion that ICT and HOT focused format is superior compared to the chalk and talk method of teaching. They are hindered by their lack of experience in using ICT to teach HOTS. One of the ESL Teachers from School A highlighted that: 
"Although we have difficulties adapting, we know that the newer ICT and HOT focused format is more effective than the old school method". [T1: SA]

Similarly, in the focus group discussions, an ESL teacher from School B stressed on the inefficient internet connection in the school. The teacher asserted that:

"Our school is provided with the internet, but we cannot use them effectively in our classes because the connection is really slow”. [T1: SB]

School D and E have insufficient netbooks and computers for activities to be conducted effectively in the classroom. A representative from School D postulated that:

"We teachers will demonstrate how to give an effective speech by ourselves. Sometimes we also ask a good students to volunteer in sharing their speeches, so the weaker students can follow". [T1: SD]

ESL teachers from School C-E stressed on the lack of necessary ICT tools to utilize the model HOTS lessons plans given by the government. One of the ESL teachers from School C postulated that:

"We do not have good internet quality here in our schools because we are in rural areas. The telecommunication coverage here is bad and the students do not know how to use computers because they do not have them at home. They are from rural backgrounds, but they are just as interested as any other student on interesting news". [T1: SC]

"We have a meeting every week for language teachers to update themselves on the latest additions or changes to the syllabus. Every week there is a 30-minute session for the language teachers to discuss on the recent changes and focus of the syllabus". [T1: SB]

However, the ESL teachers from School D and E still occasionally download sources from social media for the students to analyse, synthesise, and evaluate even when most teachers are not using ICT in the schools. An ESL teacher from School D mentioned that:

"We sometimes download articles and news from social media for students to analyse them. They are also very interested to read on the articles from social media”. [T1: SD]

Table 3. Other Challenges Faced by ESL Teachers

\begin{tabular}{lcccc}
\hline \multicolumn{1}{c}{ Types of Responses } & Agree & $\begin{array}{c}\text { Valid } \\
\text { Percent }\end{array}$ & Disagree & Valid Percent \\
\hline $\begin{array}{l}\text { Influence from } \\
\text { Colleagues }\end{array}$ & 8 & 26.7 & 22 & 73.3 \\
\hline $\begin{array}{l}\text { No Development } \\
\text { Courses }\end{array}$ & 9 & 30.0 & 21 & 70.0 \\
$\begin{array}{l}\text { School Admin does not } \\
\text { Encourage ICT Utilisation }\end{array}$ & 6 & 20.0 & 24 & 80.0 \\
$\begin{array}{l}\text { HOTS can be Promoted } \\
\text { without ICT }\end{array}$ & 27 & 90.0 & 3 & 10.0 \\
\hline Total & 30 & 100.0 & 100.0 &
\end{tabular}

Most (73.3\%) of the ESL teachers disagree that they are influenced by their colleagues who do not use ICT tools to teach HOTS. Less than one third $(30 \%)$ of the respondents agree that there are no professional development courses provided by the government. Only one-fifth (20\%) of the ESL teachers highlight that the school administrators do not encourage ICT utilisation which prevented them from effectively using ICT tools to teach HOTS. Finally, most $(90 \%)$ of the ESL teachers agree that HOTS can be promoted without ICT application.

In the qualitative results, ESL teachers from School C and D mentioned that those schools which are situated within rural areas have limited internet access. One representative from School $\mathrm{C}$ mentioned that:

"The line coverage here is terrible. It is not possible to facilitate our classes with ICT applications and it takes time to connect too. If we want to use the internet, we have to take the students to the IT lab. [T1: SC]

This data is in line with the results of the focus group discussions. Development courses are available to the teachers and those who attend courses, share the obtained information to the rest of teachers during meetings. As such, most $(70 \%)$ of the respondents disagree that there are no professional development courses provided. 
One ESL teacher from School C postulated that:

"We have teachers who volunteer to participate in conferences outside the school. Then, the ESL teachers will share the knowledge with the other ESL teachers in the school. When there are ESL teachers who did not attend the conferences, the senior teachers or ESL Master Teachers will brief us on the updates". [T1: SC]

The ESL teachers agreed that they participate in the weekly or monthly group meetings with different timings for their schools. One of the respondents from School E uttered that:

"We have general meetings for language teachers every week on Thursday after school hours. The meeting will be on the recent updates and changes into the focus and syllabus, such as the new books we will use to teach the different forms". [T1: SE]

\section{Discussion}

The main challenge experienced by ESL teachers using ICT to promote HOTS is the excessive time and effort which are necessary to integrate ICT tools into HOT pedagogy. Most of the ESL teachers (66.7\%) agreed that the additional work and time are the major deterrents, especially when they attempt to implement ICT into HOT pedagogical practices. The findings are further supported by FGD, highlighting the factors that prevent them from using any ICT to teach HOTS. In fact, ESL teachers opted not to sacrifice their time and effort, especially for thinking on the strategies for ICT implementation, as students have to be gathered before they can access the ICT laboratories. Time is also required to turn on ICT applications. The validity of the findings are highlighted in Ali (2012)'s study, which stressed that time constraint and insufficient preparation from lecturers were significant challenges for ICT implementation into HOT pedagogies. Dang (2011) also reiterated that making e-lectures and other software is rarely utilised by teachers since it requires excessive work.

Furthermore, most of the respondents (90\%) mentioned that they can still promote HOTS without ICT. The same scenario is seen in Ganapathy's (2017) study which revealed that ESL lecturers lack the necessary knowledge to innovate their pedagogical practices with HOTS and ICT implementation. In the FGDs, the ESL teachers mentioned that they use Mah-jong paper and manila cards for students to share their opinions and knowledge. This shows that ESL teachers prefer to use the traditional method of teaching as they are more comfortable with it, instead of relying on ICT tools.

Many ESL teachers $(66.7 \%)$ stressed on the unstable school internet connectivity, which discouraged the use of ICT. Also 56.7\% of the ESL teachers mentioned the lack of netbooks and computers. Hutchison \& Reinking's (2011) study confirmed that schools lack convenient access to technology. The study also remarks that according to ESL teachers in Malaysia, insufficient and inefficient access to ICT applications are among the significant drawbacks in attempting to use ICT in teaching environments. Coincidentally, a whopping (76.7\%) of ESL teachers in this study admitted that they do not know how to utilise databases in saving information.

Although many ESL teachers use notebooks and files to store data, they still need guidance from the ESL Master Teachers on the advantages of storing data online. ESL teachers from the FGD stated that they are provided with guidelines and tutorials on how to utilise the online database such as FrogVLE. Subran's (2013) study had a similar discovery too, highlighting that teachers need guidelines through professional development programmes to show them how to implement ICT effectively into their lessons. One third (36.7\%) of the ESL teachers lack the necessary skills to use effectively presentation software. They are not well-adept in using power point slides to explain their lessons. The findings are also in line with Rahaman and Akter (2017)'s study, which found that schools are not well-equipped to support ICT usage.

In short, the main challenges encountered by ESL teachers in utilising ICT to promote HOTS are the overwhelming preparation time and effort for using ICT to teach. The ESL teachers also stressed that they have other alternatives rather than using ICT, such as using physical copies over online databases.

Due to the recent shift, ESL teachers are recommended to focus on the higher level skills of Bloom's taxonomy, which are analysing, evaluating and creating information. HOTS can be taught through various active interactions, such as conducting group discussions, and power point presentations. Following the sociocultural theory and constructivist approach, more active interactions between students and teachers are necessary for the purpose of effective teaching of HOTS. Active learning can be better promoted through ICT tools, since ESL teachers can inspire the students' motivation by relevant information found and created via ICT applications. Thus, students will be able to analyse, evaluate and create information better, obtaining prior knowledge before the lessons.

In order to overcome the expected challenges when in using ICT to teach HOTS, ESL teachers' are suggested to join 
weekly discussions with other ESL teachers and to personally, in order to update themselves with the online tutorials provided by the government. Conferences and workshops on HOTS and ICT are also recommended for ESL teachers to improve their understanding of the teaching pedagogies.

\section{Conclusion}

In conclusion, ESL teachers in Malaysia face numerous challenges in promoting HOTS via ICT in schools. They need to be aware of the latest ICT pedagogical knowledge to ensure that they can teach HOTS to students effectively with the use of ICT applications as a supplementary tool. The main challenges reported by the ESL teachers are the atrocious internet connection in the schools and the lack of sufficient netbooks and computers available. The inefficient ICT equipment in schools has deterred ESL teachers from the advantages of utilising ICT in teaching the students, especially through analysing and evaluating online information. The study's results stress that there is a need for ESL teachers to update their ICT pedagogical practices to promote HOTS. The study is limited to 5 schools which are selected by the ESL Master Teachers' affiliation. The implications of the findings include, improving ESL teachers' understanding of the current challenges faced in teaching HOTS via ICT and the necessary actions which have to be taken to ensure the effectiveness of teaching critical skills with the aid of ICT applications. Further studies are needed to investigate whether pedagogical practices of ESL teachers in ICT are dependent on the school's location and how the teaching experience of ESL teachers affect their ICT pedagogical practices in promoting HOTS.

\section{References}

Ali, S. N. (2012). Malaysian polytechnic lecturers' teaching practices with ICT utilization to promote higher-order thinking skills. (Published Doctoral Dissertation, IOWA State University). Retrieved from http://lib.dr.iastate.edu/cgi/viewcontent.cgi?article=3630\&context=etd

Bakar, A. R., \& Mohamed, S. (1998). Preparing Malaysian vocational and technology teachers to integrate computer technology in teaching vocational and technology subjects. Computers \& Education, 31(4), 365-372. https://doi.org/10.1016/S0360-1315(98)00023-2

Bloom, B. S. (1956). Taxonomy of educational objectives. Vol. 1: Cognitive domain. New York: McKay.

Collins, R. (2014). Skills for the 21st Century: Teaching higher-order thinking. Curriculum \& Leadership Journal, 12(14), 1.

Dang, X. T. (2011). Factors influencing teachers' use of ICT in language teaching: A case study of Hanoi University, Vietnam. In International Conference "ICT for Language Learning" 4th edition, Simonelli Editore, Hanoi, Vietnam 20-21 October, 2011.

Education Development Plan for Malaysia, 2001-2010.

Education Development Plan for Malaysia, 2011-2020.

Fischer, C. (2011). An investigation of higher-order thinking skills in smaller learning community social studies classrooms. American Secondary Education, 39(2), 5-26.

Ganapathy, M., \& Kaur, S. (2014). ESL Students' Perceptions of the use of Higher Order Thinking Skills in English Language Writing. Advances in Language and Literary Studies, 5(5), 80-87. https://doi.org/10.7575/aiac.alls.v.5n.5p.80

Ganapathy, M., Kaur, M., Kaur, S., \& Liew, W. K. (2017). Promoting Higher Order Thinking Skills via Teaching Practices 3L. The Southeast Asian Journal of English Language Studies 23(1), 75-85. https://doi.org/10.17576/3L-2017-2301-06

Guerriero, S. (2014). Teachers' Pedagogical Knowledge and the Teaching Profession. Innovative Teaching for Effective Learning (ITEL) Programme. Centre for Educational Research and Innovation (CERI). Retrieved from http://www.oecd.org/edu/ceri/Background_document_to_Symposium_ITEL-FINAL.pdf

Hargreaves, A., Earl, L., \& Schmidt, M. (2002). Perspectives on Alternative Assessment Reform. Ontario Institute for Studies in Education, University of Toronto. Texas A\&M University. American Educational Research Journal Spring, 39(1), 69-95. https://doi.org/10.3102/00028312039001069

Hilbert, M. (2015). Big Data for Development: A Review of Promises and Challenges. Dev Policy Rev, 34(1), 135-174. https://doi.org/10.1111/dpr.12142

Hutchison, A., \& Reinking, D. (2011). Teachers' perceptions of integrating information and communication 
technologies into literacy instruction: A national survey in the United States. Reading Research Quarterly, 46(4), 312-333. https://doi.org/10.1002/RRQ.002

Hwa, Y. Y. (2016). From drills to skills? Cultivating critical thinking, creativity, communication, and collaboration through Malaysian schools. Penang Institute Working Paper, Penang Institute, Kuala Lumpur, 10.

Kotrlik, J., Harrison, B., \& Redmann, D. (2000). A comparison of information technology training sources, value, knowledge, and skills for Louisiana's secondary vocational teachers. Journal of Vocational Education Research, 25(4), 396-444. https://doi.org/10.5328/JVER25.4.396

Loyens, S. M., Kirschner, P. A., \& Paas, F. (2012). Problem-based learning. In APA educational psychology handbook, 3. Application to learning and teaching, 403-425. American Psychological Association. https://doi.org/10.1037/13275-016

Omar, W. (2017). Higher Education 4.0: Current Status and Readiness in Meeting the Fourth Industrial Revolution Challenges. Redesigning Higher Education Towards Industry 4.0, Kuala Lumpur, Malaysia, 23-24 August 2017, University Presidential forum 2017. Universiti Teknologi Malaysia.

Rahaman, M. M., \& Akter, N. (2017). ICT Used In Education Sector Considering Primary and Secondary Level Schools in Rural Areas: A Study of Sylhet Division in Bangladesh. IOSR Journal of Business and Management (IOSR-JBM), 19(4), 1-6. https://doi.org/10.9790/487X-1904020106

Rajeendram, R. (2018, April 8). Key to higher order thinking skills. The Star Online. Retrieved from https://www.thestar.com.my/news/education/2018/04/08/key-to-higher-order-thinking-skills/

Savery, J. R. (2015). Overview of problem-based learning: Definitions and distinctions. Essential readings in problem-based learning: Exploring and extending the legacy of Howard S. Barrows, 9, 5-15. https://doi.org/10.7771/1541-5015.1593

Seaman, M. (2011). Bloom's Taxonomy: Its evolution, revision and use in the field of education. Curriculum and Teaching Dialogue, 13(1-2), 29-131.

Sharmila, S. (2017). A study on stress level of college students. International Journal of Social Sciences, 5(5), 136-137.

Subran, D. (2013). Developing higher-order thinking with ICT. Retrieved from: http://hdl.handle.net/2139/15701

Zakri, A. H. (2017, December 4). 4th Industrial revolution and the age of optimisation. News Straits Times. Retrieved from: https://www.nst.com.my/opinion/columnists/2017/12/310438/4th-industrial-revolution-and-age-optimisation

Zohar, A. (2013). Challenges in wide scale implementation efforts to foster higher order thinking (HOT) in science education across a whole school system. Thinking Skills and Creativity, 10, 233-249.

https://doi.org/10.1016/j.tsc.2013.06.002 